\title{
Influence of soil moisture content on surface albedo and soil thermal parameters at a tropical station
}

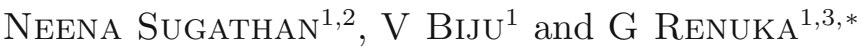 \\ ${ }^{1}$ Department of Physics, University of Kerala, Kariavattom Campus, Thiruvananthapuram 695581 , Kerala, India. \\ ${ }^{2}$ Department of Physics, Government College for Women, Thiruvananthapuram 695 014, Kerala, India. \\ ${ }^{3}$ Kerala State Council for Science, Technology and Environment, Sasthra Bhavan, Pattom, \\ Thiruvananthapuram 695 004, Kerala, India. \\ *Corresponding author.e-mail: drgrenuka@gmail.com
}

Half hourly data of soil moisture content, soil temperature, solar irradiance, and reflectance are measured during April 2010 to March 2011 at a tropical station, viz., Astronomical Observatory, Thiruvananthapuram, Kerala, India ( $76^{\circ} 59^{\prime} \mathrm{E}$ longitude and $8^{\circ} 29^{\prime} \mathrm{N}$ latitude). The monthly, seasonal and seasonal mean diurnal variation of soil moisture content is analyzed in detail and is correlated with the rainfall measured at the same site during the period of study. The large variability in the soil moisture content is attributed to the rainfall during all the seasons and also to the evaporation/movement of water to deeper layers. The relationship of surface albedo on soil moisture content on different time scales are studied and the influence of solar elevation angle and cloud cover are also investigated. Surface albedo is found to fall exponentially with increase in soil moisture content. Soil thermal diffusivity and soil thermal conductivity are also estimated from the subsoil temperature profile. Log normal dependence of thermal diffusivity and power law dependence of thermal conductivity on soil moisture content are confirmed.

\section{Introduction}

Soil moisture is an important parameter that determines the microclimate of a region. In comparison with soil temperature, which is the most commonly recorded and studied soil thermal parameter, the soil moisture content varies rather slowly with changes in the land-atmosphere system. The relatively longer memory of soil moisture in comparison with the variation of controlling parameters often leads to climatic anomalies. The solar energy incident on the surface is divided into soil heat flux, latent heat flux, and sensible heat flux. Surface albedo, $\alpha$ defined as the fraction of the incident solar radiation that is reflected from the surface plays a major role in the energy balance of the soil surface and boundary layer climate of the region. Surface albedo at a location varies with the changing solar elevation angle, soil moisture content, soil texture, the type and condition of vegetation covering soil surface, organic matter content, mineral composition, etc. The moisture content and vegetation cover changes the soil colour and thus varies the surface albedo (Todd and Hoffer 1998). The diurnal and seasonal variation of surface albedo of bare soil is primarily due to changes in the solar elevation angle and the soil moisture content. Also, the soil thermal parameters such as thermal diffusivity, $D_{T}$ and thermal conductivity, $k$ which determine the thermal profile of subsurface layers at a location are profoundly influenced by the soil moisture content.

The dependence of bare soil albedo on the soil moisture content was recognized by Angstrom in

Keywords. Land surface processes; surface albedo; soil moisture; soil thermal parameters. 
1925 and the first laboratory scale investigation to elucidate the relationship is due to Bowers and Hanks (1965). A systematic investigation of the exact relationship between surface albedo and soil moisture based on field experiments was carried out at Phoenix, Arizona Avondale loam soil (Idso et al. 1975) in which a fall in albedo with increase in moisture content was observed. Studies on the dependence of soil thermal parameters on soil moisture content have also been reported for different kinds of soils over the years (Kasubuchi 1975; Usowicz 1993; Usowicz et al. 2013; Anandakumar et al. 2001; Wang and Shen 2013). In recent past, studies which included the combined analysis of the dependence of surface albedo and soil thermal parameters on the soil moisture content at sites with distinctly different geographical and climatic features have appeared in the literature. Detailed investigation of surface albedo and its dependence on soil moisture at degraded grass land and crop land surfaces in a semi-arid area of Tognyu was reported by Liu et al. (2008a) and concluded that the surface albedo decreases with increases in soil moisture content below the field capacity. Also, the soil thermal diffusivity was found to increase with increase in soil moisture content up to a particular value and then decrease with further increase in moisture content while no mathematical relation accounting for the empirical observation was suggested. They also reported a power law dependence for soil thermal conductivity on moisture content with small exponents $\sim 0.05$ (Liu et al. 2008a). Wang et al. (2005) had done a detailed study of the seasonal and annual variations of surface albedo and soil thermal parameters with soil moisture content at a semi-desert site in the western Tibetan plateau. Here also an exponential fall of surface albedo with soil moisture content and power law dependence for soil thermal conductivity was observed. Further, it was shown that the soil thermal diffusivity first increases with increase in soil moisture content, reaches a maximum value and thereafter falls with further increase in the moisture content following a log normal function (Wang et al. 2005). Similar studies at semi-arid areas in north-eastern China (Liu et al. 2008b) and over Loess Plateau at north-west China (Guan et al. 2009) have been reported where the exponential fall of surface albedo was observed. The dependence of soil thermal diffusivity on soil moisture content at Loess Plateau was reported to be a linearly increasing one (Guan et al. 2009). All these reports refer to experimental sites in the mid-latitude (Huang et al. 2008), mostly semiarid or semi-desert in nature and similar studies in the Tropical regions (latitude less than $23^{\circ}$ north/south) are comparatively less in number. Gascoin et al. (2009) had studied the dependence of surface albedo on soil moisture content at an experimental site on the moraine of Zongo Glacier in Bolevia, a tropical site $\left(68^{\circ} 10^{\prime} \mathrm{W}, 16^{\circ} 15^{\prime} \mathrm{S}\right)$ and obtained an exponential fall of surface albedo with soil moisture content. They pointed out the significant difference in the fitting parameters in comparison with those corresponding to the semidesert regions in midlatitude regions (Wang et al. 2005) and the large variability of soil moisture content at the tropical site result in scattering of points about the exponential fit (Gascoin et al. 2009). From the available literature, it is clear that the exact dependence of surface albedo on soil moisture content is site specific. The relationship between soil moisture content and soil thermal diffusivity is rather complex. In some cases, the diffusivity is found to increase linearly with moisture content (Guan et al. 2009) while at other locations an increase followed by a fall is reported (Wang et al 2005). Soil thermal conductivity is reported to increase with increase in moisture content and the dependence could be linear or nonlinear (Wang et al (Wang et al. 2005); Liu et al 2008b).

As the surface albedo and soil thermal parameters are important factors in climate modelling and weather forecasting, investigation of the influence of soil moisture on them at different time scales viz., diurnal, seasonal, and annual - at different locations is interesting from both academic and application points of view. Such studies are important in developing soil temperature based weather prediction models and also in fields such as agriculture, geotechnical engineering, etc. (Tessy Chacko and Renuka 2002; Gascoin et al. 2009). Herein, we report the seasonal, monthly, and diurnal variation of soil moisture content and its influence on the surface albedo at an experimental site in Thiruvananthapuram, Kerala, south India. The dependence of soil thermal parameters on the soil moisture content is also studied. Parameters such as air temperature, humidity, precipitation, and net radiation are influenced by the rates at which solar energy, water vapour, and heat fluxes are exchanged between land and the atmosphere (Baldocchi et al. 1997). Steady state of the atmospheric boundary layer is determined by the surface fluxes of momentum, heat, and moisture, which in turn depend on the soil thermal parameters and hence on the soil moisture content. Thus, the dependence of surface albedo and soil thermal parameters on soil moisture content is one important aspect of climate change research (Wang et al. 2010). Studies on different geographical locations and soil types are important in enhancing prediction abilities by improving land-surface parameters in atmospheric numerical models (Robock et al. 2000). Thus, the present work could contribute data and results relevant for improving the land atmosphere interactions 
in tropical regions. Also, Thiruvananthapuram, in the southern part of India close to the Arabian Sea, is where Vikram Sarabhai Space Centre, Indian Space Research Organization, one important site for ground-based studies of atmospheric boundary layer, aerosols, etc., is located, making this work relevant and interesting.

\section{Site description, instrumentation and data}

Astronomical Observatory, University of Kerala, Thiruvananthapuram, Kerala, south India located at $76^{\circ} 59^{\prime} \mathrm{E}$ longitude and $8^{\circ} 29^{\prime} \mathrm{N}$ latitude is the study site. It is nearly $8.4 \mathrm{~km}$ inland from the Arabian Sea and is situated at $64.31 \mathrm{~m}$ above the mean sea level. The colour of the soil at the experimental site varied from dark brown to dark reddish brown. Soil texture analysis revealed that the soil at the experimental site is of sandy clay type $(59.73 \%$ sand, $38.50 \%$ clay and $1.77 \%$ silt). Organic matter content is $1 \%$ while porosity and particle density are respectively $60.70 \%$ and $2.50 \mathrm{~g} / \mathrm{cc}$. The bulk density, $\rho_{b}$ and field capacity values estimated are $1330 \mathrm{~kg} / \mathrm{m}^{3}$ and $0.3 \mathrm{~m}^{3} / \mathrm{m}^{-3}$, respectively. Astronomical Observatory is situated in the same campus of India Meteorological Department (IMD), Thiruvananthapuram where daily meteorological data are recorded and hence have the advantage that their measurements well complement our measurements. Daily rainfall data and cloud cover data recorded by IMD, Thiruvananthapuram were used for analysis. This study used data recorded during the period April 2010-March 2011.

The climate of the state of Kerala, India is tropical maritime and monsoonal in nature (Menon and Rajan 1989). It is characterized by high temperature and humidity throughout the year. The climate is characterized by two rainy seasons: southwest (SW) monsoon (June-September) and northeast (NE) monsoon (October-November). Thunderstorm activity is common during premonsoon (March-May). Winter (DecemberFebruary) comes after two rainy seasons and corresponds to minimum rainfall. Rainfall is abundant with rain for nearly 10 months of the year with average precipitation of about $3000 \mathrm{~mm}$ per year. Based on soil temperature, Kerala is classified under the iso-hyperthermic regime with an annual soil temperature equal to or greater than $22^{\circ} \mathrm{C}$ and the mean soil temperatures of June-August and December-February differ less than $5^{\circ} \mathrm{C}$ at a depth of $50 \mathrm{~cm}$ or at lithic or paralithic contact whichever is shallower. Based on moisture, Kerala falls under the ustic regime.

A computer-controlled hydrometeorological data acquisition system from Environmental Measurements and Controls (EMCON) Cochin, India was installed at the experimental site. The parameters measured are (i) soil moisture at depths of 5, 10, 20, 30 and $50 \mathrm{~cm}$; (ii) soil temperature at depths of 2.5 , $5,10,20,30$ and $50 \mathrm{~cm}$; (iii) solar irradiation and (iv) solar reflectance. All parameters were continuously measured at half hourly intervals. The soil moisture content expressed as the mass percentage, $\theta_{m}$, was measured using sensors based on soil impedance. The excitation of sensors was effected by sinusoidal signals of fixed frequency so as to eliminate polarization effects. This ensured long term consistency. The inherent nonlinearity in the performance of the moisture sensor was eliminated by an embedded system based signal conditioning. The sensors could accurately measure soil moisture content in the range $0-50 \%$ with an accuracy of $\pm 0.2 \%$ and resolution of $0.1 \%$ in the temperature range 0- $60^{\circ} \mathrm{C}$. Soil temperature measurements were done using $\mathrm{p}-\mathrm{n}$ junction sensors encapsulated in stainless steel covers filled with silicon. The encapsulation and the filler ensured good thermal contact and longevity against high geostatic pressure. The resolution and accuracy of soil temperature measurement is $0.1^{\circ} \mathrm{C}$ and $\pm 0.2^{\circ} \mathrm{C}$, respectively. Wide spectrum (short wave) photodiode based sensors were employed for measuring the solar incidence and solar reflectance. Both sensors have an accuracy of $\pm 1 \mathrm{Wm}^{-2}$ and a resolution of $1 \mathrm{Wm}^{-2}$. The interval of measurement can be varied from the order of minutes to hours and was kept as half an hour in this study. The sensors have been tested and calibrated at regular intervals and the linearity

Table 1. The measurement instruments (EMCON make) and quantities measured.

\begin{tabular}{lllll}
\hline $\begin{array}{l}\text { Parameter } \\
\text { variable }\end{array}$ & Range & $\begin{array}{l}\text { Accuracy, } \\
\text { resolution }\end{array}$ & Unit & Instrument \\
\hline $\begin{array}{l}\text { Soil moisture content } \\
(\text { mass \%) }\end{array}$ & $0-50 \%$ & $\pm 0.2 \% ; 0.1 \%$ & $\mathrm{~g}^{3} \mathrm{~g}^{-3}$ & Soil impedance meter \\
$\begin{array}{l}\text { Soil temperature } \\
\text { measurement }\end{array}$ & $60^{\circ} \mathrm{C}$ & $\pm 0.2^{\circ} \mathrm{C} ; 0.1^{\circ} \mathrm{C}$ & ${ }^{\circ} \mathrm{C}$ & $\mathrm{p}-\mathrm{n}$ junction diode \\
$\begin{array}{l}\text { Incident and reflected } \\
\text { shortwave radiation }\end{array}$ & $0-1200 \mathrm{Wm}^{-2}$ & $\pm 1 \mathrm{Wm}^{-2} ; 1 \mathrm{Wm}^{-2}$ & $\mathrm{Wm}^{-2}$ & Photodiode sensor \\
\hline
\end{tabular}


and sensitivity mentioned are certified by India Meteorological Department (IMD), Pune. Details of the measuring instruments are summarized in table 1. Due to malfunctioning and quality assurance/quality control (QA/QC), there is about $81 \%$ good data for the period of study. To complement the data measured, the daily rainfall and cloud cover data from IMD, Thiruvananthapuram were also used.

\section{Method}

\subsection{Soil moisture}

The volumetric soil moisture content, $\theta_{v}$, was estimated from the soil moisture percentages $\left(\theta_{m}\right)$ using the relation $\theta_{v}=\left(\rho_{b} / \rho_{w}\right) \theta_{m}$, where $\rho_{w}$ is the density of water and $\rho_{b}$ is the bulk density of soil (Hillel 2004). The bad data points due to malfunction were removed from the used dataset. The maxima and minima values of soil moisture during the study period are respectively $41.25 \%$ and $7.45 \%$ which fall in the range of measurement for the sensors used.

\subsection{Surface albedo}

Surface albedo, $\alpha$, was calculated from the measured solar incidence, $S_{i}$ and solar reflected, $S_{r}$ as:

$$
\alpha=S_{r} / S_{i}
$$

As the surface albedo varies with solar elevation angle, in order to study the variation of surface albedo with moisture, first the exact dependence of surface albedo on solar elevation angle was studied and the influence of moisture was investigated using the data points recorded when the effect of solar elevation angle was minimal.

\subsection{Soil thermal parameters}

Thermal diffusivity, $D_{T}$ and thermal conductivity, $k$ are the two most important soil thermal parameters that determine the soil thermal profile and its variation at different time scales. Both these parameters depend on the mineral content and the percentage of organic content. However, the diurnal, seasonal, and annual variations are mostly affected by variations in the soil moisture content. Direct measurement of soil thermal diffusivity in the field is difficult and hence it is often estimated from the soil thermal measurements at different depths. The propagation of thermal wave into the soil is approximated as conductive heat transfer in a one-dimensional isotropic medium and can be modelled as (Horton et al. 1983):

$$
\frac{\partial T}{\partial t}=D_{T} \frac{\partial^{2} T}{\partial z^{2}}
$$

Here $T$ is the soil temperature, $D_{T}$ is the soil thermal diffusivity, $t$ the time and $z$ the depth. Soil thermal diffusivity can be estimated from the soil thermal measurements at different depths using a number of methods such as the decrease of amplitude, phase difference, time lag, etc. By solving equation (2), the amplitude of thermal wave, $A$ at any depth $z$ is related to the amplitude at the surface, $A_{0}$ as:

$$
A=A_{0} \exp \sqrt{\frac{\omega}{2 D_{T}} Z} .
$$

Here $\omega$ is the angular frequency of the earth's rotation. From equation (3), the soil thermal diffusivity is given by:

$$
D_{T}=\frac{\omega}{2}\left[\frac{z}{\operatorname{In}\left(A / A_{0}\right)}\right]^{2} .
$$

Soil thermal diffusivity in the present study was estimated from the soil temperatures recorded at the surface and $10 \mathrm{~cm}$ depths using the Amplitude method (Horton et al. 1983).

Soil thermal conductivity, $k$, is the product of soil thermal diffusivity, $D_{T}$, and volumetric heat capacity, $C_{v}$. For estimating soil thermal conductivity, volumetric heat capacity was calculated using the expression $C_{v}=837 \rho_{b}+4.19 \times \theta_{v}$, where $\rho_{b}=1330 \mathrm{~kg} / \mathrm{m}^{3}$ is the bulk density of soil (Hillel 2004).

\section{Results and discussion}

\subsection{Monthly, seasonal and diurnal variations of soil moisture}

The monthly and seasonal variations of volumetric soil moisture content at different depths during the period April 2010-March 2011 are shown in figures 1 and 2, respectively. Total rainfall during the study period at Thiruvananthapuram is $1858 \mathrm{~mm}$. Total rainfall per month/season is also included in the respective plots for comparison. It is clear from figure 1 that the amount of rainfall in different months affects the moisture content at all depths. The monthly variation of soil moisture content at different depths is almost consistent. The moisture content at $5 \mathrm{~cm}$ depth, the layer closer to the surface is smaller in comparison with that at deeper layers in all the months. This is an indication of the rapid drying up of surface soil due to solar irradiation. Another factor that contributes to the observed moisture profile is the fact that the soil supports the movement of water into deeper layers (Roxy et al. 2010). This is more pronounced during the monsoon months where there is a sudden rise in the moisture content at $10 \mathrm{~cm}$ depth 


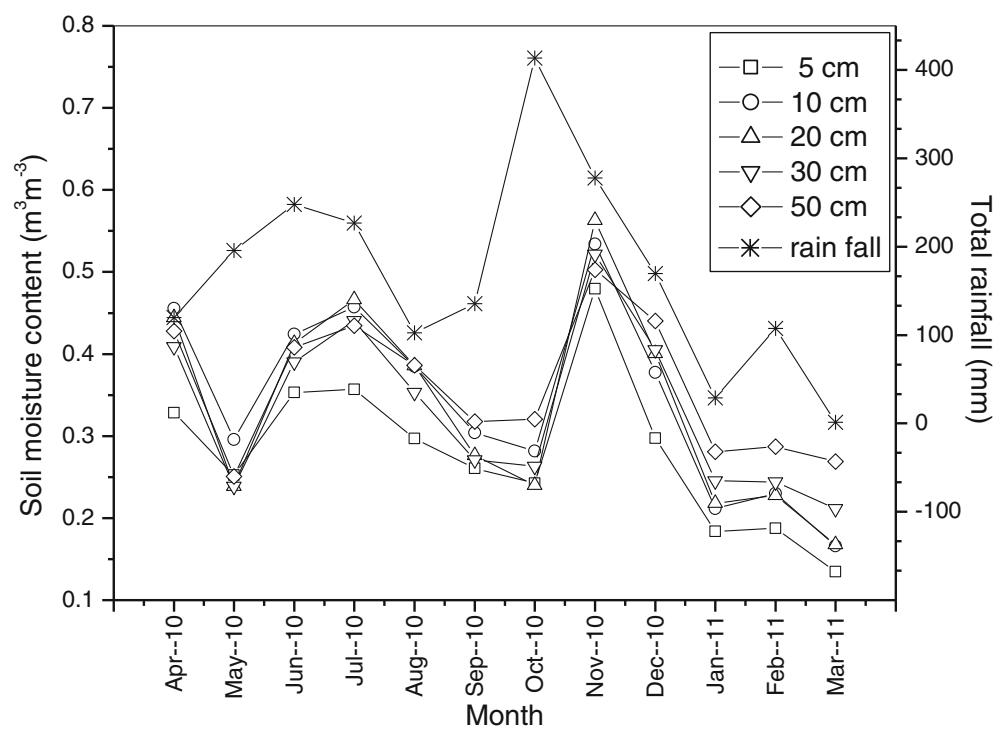

Figure 1. Monthly variation of soil moisture content at different depths and total rainfall.

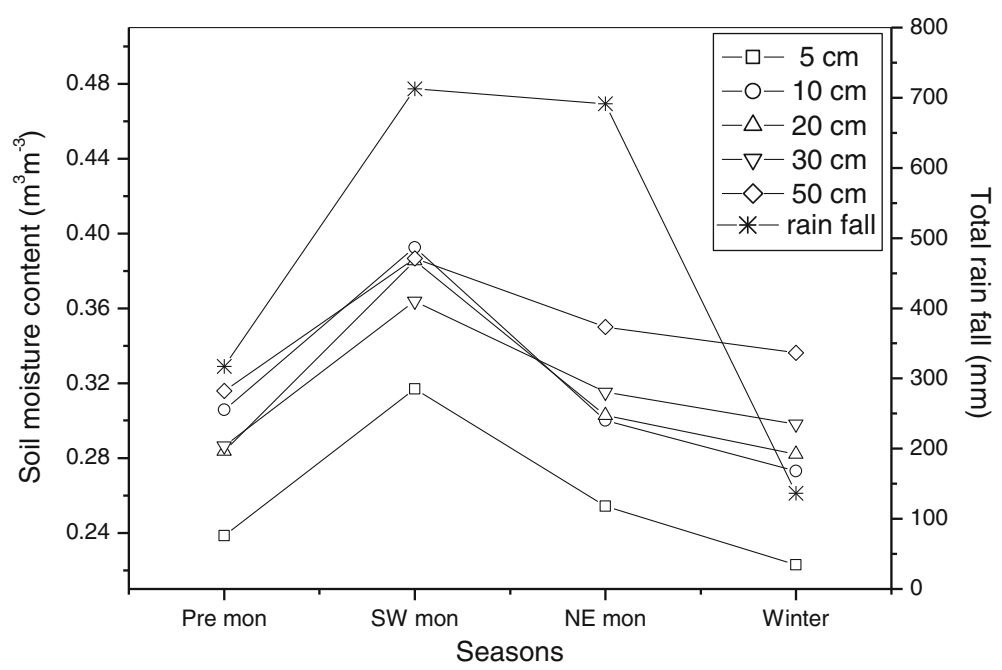

Figure 2. Seasonal variation of soil moisture content at different depths and total rainfall.

which in some months is even higher than that at $20 \mathrm{~cm}$. During the winter months, December to February, the soil moisture content at $50 \mathrm{~cm}$, is the highest. This is because the winter months succeed two rainy seasons and the soil moisture at deeper layers has a longer memory compared to shallower ones.

In the seasonal variation of moisture (figure 2) also, the variation at all depths is consistent with the variation of the total rainfall. Further, the values corresponding to pre-monsoon and winter are relatively smaller compared to the monsoon seasons. At 5 and $10 \mathrm{~cm}$ depths, the moisture content is minimum for the winter season followed by pre-monsoon. At $20 \mathrm{~cm}$ depth, the moisture content during pre-monsoon and winter are almost the same. For deeper layers, viz., 30 and $50 \mathrm{~cm}$, the moisture content is least during pre-monsoon. The moisture content at all layers is maximum during SW monsoon which received the maximum rainfall. During NE monsoon months these are slightly lower than SW monsoon and fall to still lower levels during winter. For the deeper layers, viz., 30 and $50 \mathrm{~cm}$, the soil moisture content is minimum during the pre-monsoon season. As already pointed out, the larger value of soil moisture at deeper layers during winter which follows the monsoon seasons in comparison with that during pre-monsoon is due to the longer memory of the soil moisture. An analysis of the depth profile of soil moisture content during the four seasons shows that the moisture content is always minimum at $5 \mathrm{~cm}$ and this is due to the rapid evaporation from the surface and the movement of water to deeper layers. A 
comparison of figures 1 and 2 clearly shows that the correlation between total rainfall and soil moisture content at all layers is better at seasonal scale compared to monthly scale. This is an indication of the relatively slow varying nature of soil moisture content. In figure 1, the total rainfall during October 2010 is maximum $(413.5 \mathrm{~mm})$ while the soil moisture content at all layers is rather low. This happened because during October 2010, good data was available only for 11 days (October 21-31) due to malfunctioning/QA/QC and no interpolation scheme employed for filling the missing data points as heavy rainfall had occurred during the missing period. Also, during May 2010, the total monthly rainfall is $195 \mathrm{~mm}$, higher than that for April 2010 $(120 \mathrm{~mm})$ while the average soil moisture content at all depths have lower values. This happened because, majority of rainfall $(122.8 \mathrm{~mm})$ occurred during 25-30 May with $52.5 \mathrm{~mm}$ rain on 30th alone. In April 2010, major rainfall occurred during the middle of the month, viz., 17 th $(34.6 \mathrm{~mm})$ and $18 \mathrm{th}$ $(32.8 \mathrm{~mm})$. This resulted in an apparent discrepancy in figure 1 where average monthly moisture content is compared to total monthly rainfall.
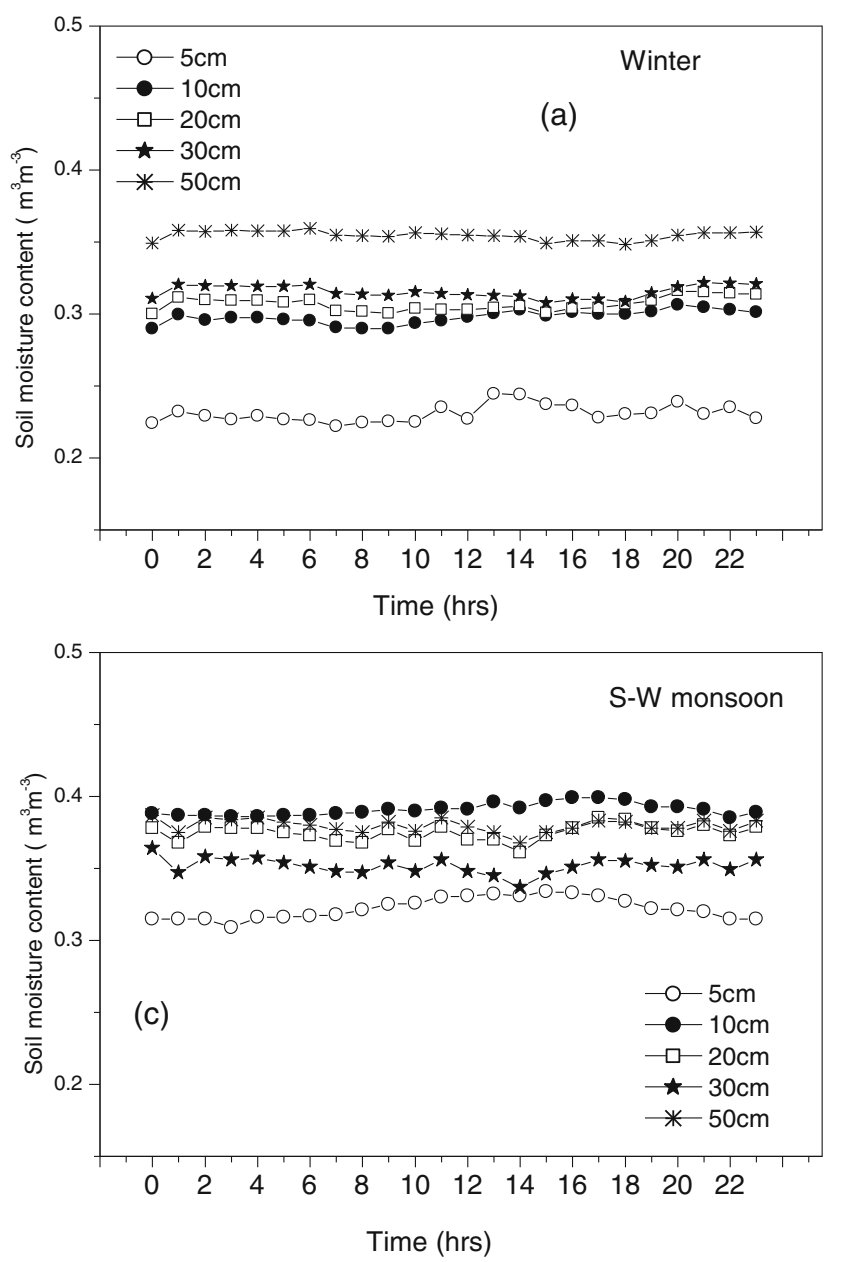

Seasonal mean of diurnal soil moisture content at different depths during different seasons are plotted in figure $3(\mathrm{a}-\mathrm{d})$. Though the pattern of diurnal variation does not change much, the distinctly different soil moisture contents during the four seasons is clearly evident from the plots. During premonsoon, the soil moisture values lie in the range $0.224-0.316$. The range for $\mathrm{SW}$ monsoon and NE monsoon are, respectively, 0.309-0.399 and 0.2900.416 . During winter the range is $0.222-0.359$. The soil moisture content at $5 \mathrm{~cm}$ is lower than that at shallower layers during all the seasons due to the fast evaporation. Further, it is also clear that diurnal variation at all depths, shallow or deep, does not vary much during any season. Unlike soil temperature, the amplitude of moisture wave is not discernable in the present study. A similar study at Loess Plateau, China had reported that the soil moisture wave features are discernable at $5 \mathrm{~cm}$ depth while at a deeper layer, the diurnal variation was practically unnoticeable (Guan et al. 2009). This underlines the site dependent nature of the diurnal variation of seasonal mean of soil moisture content.
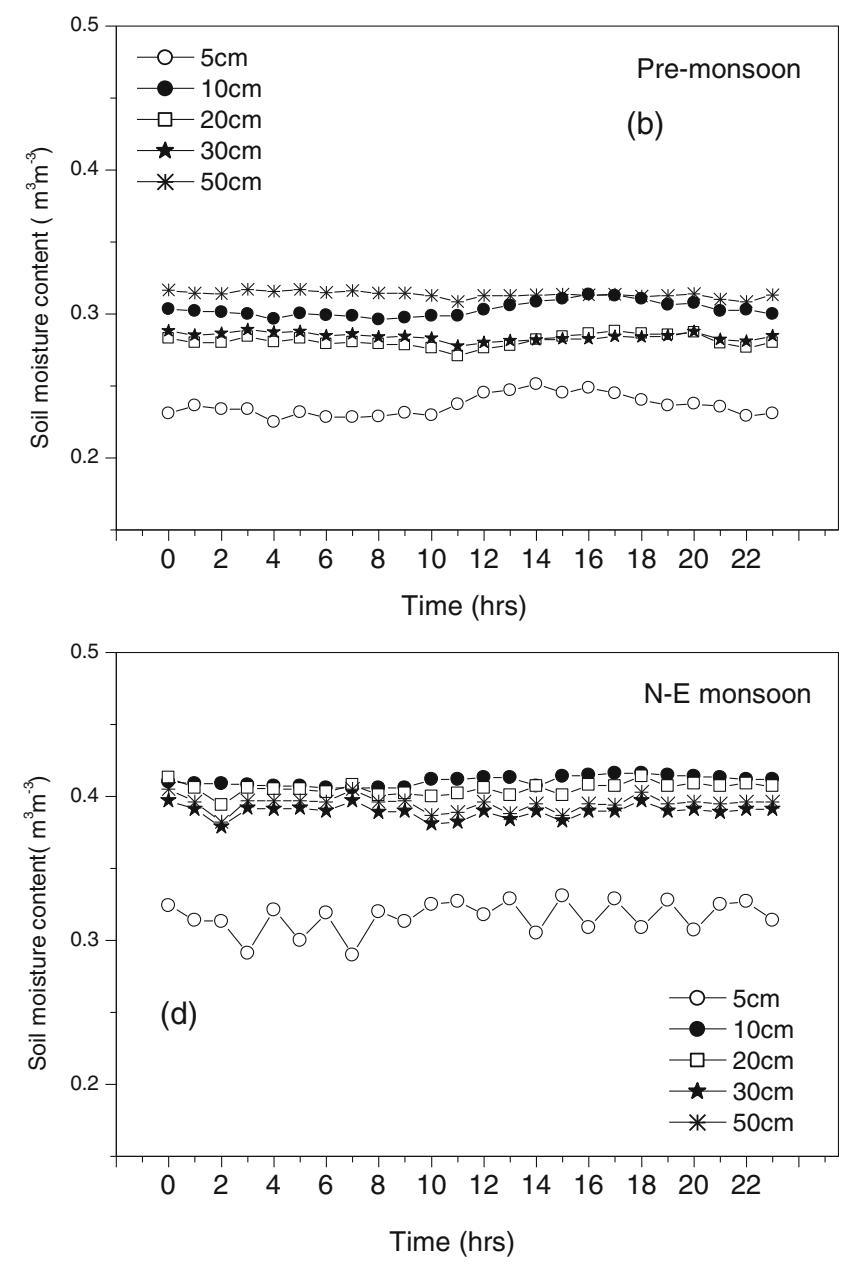

Figure 3. Seasonal mean of diurnal soil moisture content at different depths. 
In order to study the variability of soil moisture content during different seasons, the standard deviation of diurnal soil moisture content during different seasons are estimated. Figure $4(\mathrm{a}-\mathrm{d})$ shows the seasonal mean of diurnal soil moisture content at $5 \mathrm{~cm}$ together with the standard deviation. The daily average of standard deviation of soil moisture content at $5 \mathrm{~cm}$ depth for winter and pre-monsoon are 0.11 and 0.13 , respectively. The corresponding values during SW monsoon and NE monsoon are slightly less, viz., 0.10 and 0.09 , respectively. Slightly lower variability of soil moisture content during the two monsoon seasons leads to the inference that increase in rain decreases variability and variability is an indication of the balance between precipitation, evaporation, and movement of water to deeper layers. Guan et al. (2009) reported the standard deviations for the diurnal variation of moisture content at $5 \mathrm{~cm}$ layer at Loess Plateaue, a semi-arid region and showed a notable difference during different seasons and confirmed that during seasons with rain the variability is relatively larger. This is in contrast with our result where we have observed a smaller deviation in monsoon seasons compared to pre-monsoon and winter. Further, compared to the semi-arid region, the variability of soil moisture content is higher during all seasons in this study. This could be due to the fact that in this site, some rainfall occurs
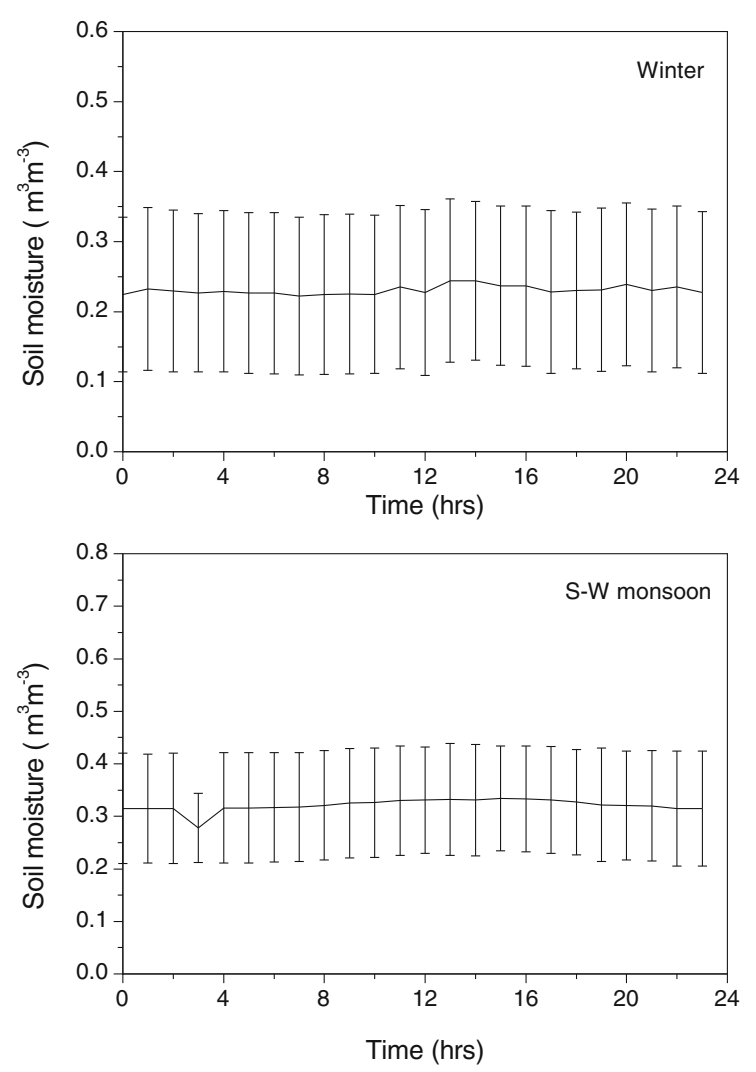

during almost all months and also due to the tropical nature evaporation plays a major role in determining the variability of soil moisture content.

To study the variability in mean diurnal soil moisture, the ratio of standard deviation to average moisture content at each depth during the four seasons are plotted in figure 5 . It is clear that the variability changes with depth. In general, the variability during pre-monsoon and winter is higher

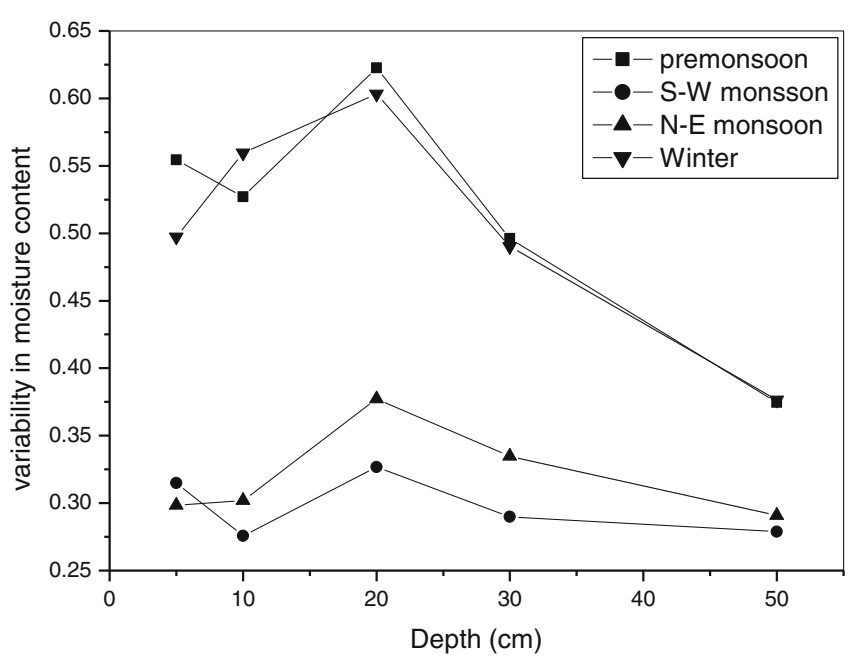

Figure 5. Variability of mean diurnal soil moisture at different depths.
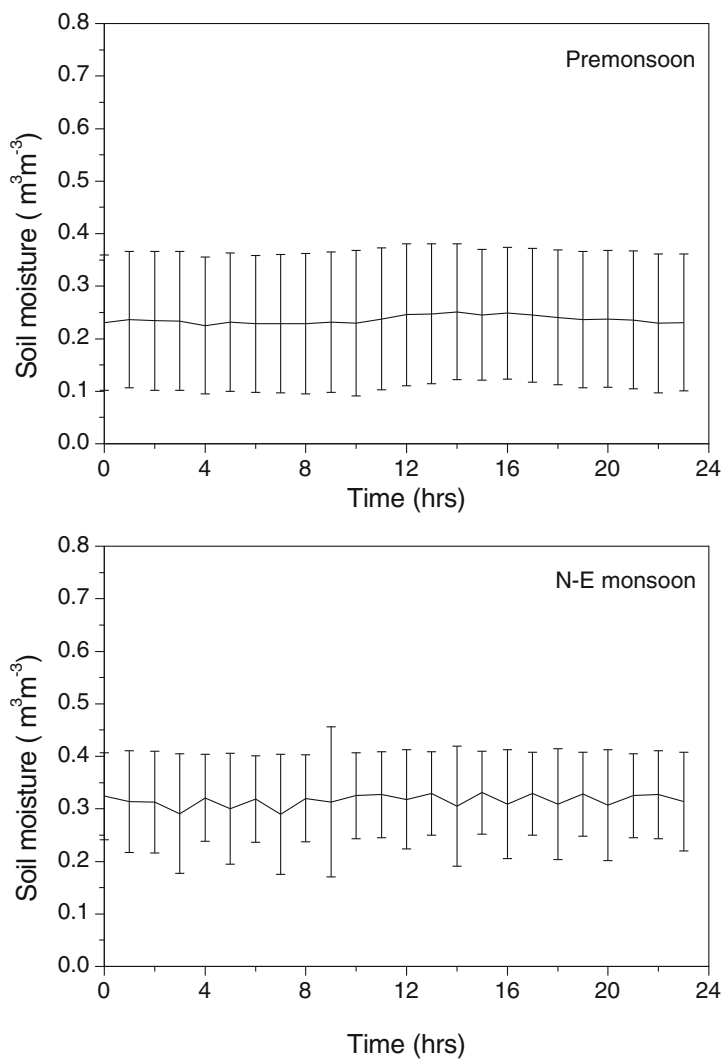

Figure 4. Standard deviation for the seasonal mean of diurnal soil moisture content at $5 \mathrm{~cm}$ depth. 
than that for the two monsoon seasons. This supports our argument that more precipitation decreases the variability in soil moisture content. Further, the variability at $10 \mathrm{~cm}$ is slightly less than that at $5 \mathrm{~cm}$ during pre-monsoon and SW monsoon. This is because of the high evaporation from the layer close to the surface. However, the variability is maximum for all seasons at $20 \mathrm{~cm}$. This shows that the movement of water into deeper layers also contributes significantly to the variability of moisture content. Lesser variability of moisture content at deeper layers, viz., 30 and $50 \mathrm{~cm}$ is because of very low evaporation and longer memory.

\subsection{Variation of surface albedo with solar elevation angle and soil moisture content}

\subsubsection{Surface albedo and solar elevation angle}

Surface albedo, $\alpha$, at any location changes with the solar elevation angle, $\varphi$, diurnally and seasonally. To study the dependence of albedo on soil moisture, first the dependence of albedo on solar elevation angle should be studied and excluded ( $\mathrm{Li}$ and $\mathrm{Hu}$ 2009). The surface albedo at half hourly intervals is estimated from the solar irradiance and solar reflectance using equation (1). The half hourly values of solar elevation angle at this site during the study period are estimated from the longitude, latitude, and Julian day (Oke 1987). The variation of surface albedo with solar elevation angle is plotted in figure 6. Sharp peaks in albedo were removed from the curve to obtain the general dependence. Fitted surface albedo, $\alpha$ as a function of solar elevation angle, $\varphi$ gives the relation, $\alpha=$ $0.2925+0.36867 \exp (-\varphi / 4.65833)$. The squared correlation coefficient for the fit is 0.66. Surface albedo falls sharply till the solar elevation angle reaches $\sim 10^{\circ}$ and thereafter gradually falls till $20^{\circ}$. In the range, $\varphi>50^{\circ}$, surface albedo is almost independent of the solar elevation angle as clearly seen in figure 6 . The bi-directional reflectance character is an intrinsic characteristic of the soil surface (Liang and Townshend 1996) and surface albedo is the average of the bidirectional reflectance over the reflected hemisphere. Thus, although the bidirectional reflectance shows a rather large variation in the reflected hemisphere, the variation of the albedo is very less in the range mentioned. However, even in the range $\varphi>50^{\circ}$, the measured surface albedo shows relatively large scattering about the fitted curve. This could be due to the higher variability of moisture content in this site which significantly affects the surface albedo resulting in relatively large scattering of data points even at higher solar elevation angles.

\subsubsection{Surface albedo and soil moisture content}

The daily variation of surface albedo with soil moisture content at $5 \mathrm{~cm}$ during the period of study is shown in figure 7 . The correlation coefficient for the two time series is -0.5273 . In order to study the influence of solar elevation angle, the daily average surface albedo and soil moisture content were estimated using the data under the constraint that the solar elevation angle, $\varphi>50^{\circ}$. The correlation coefficient between the surface albedo and soil moisture content is now -0.5306 which is only marginally greater than that in the previous case. The dependence of surface albedo on solar elevation angle is not reflected in the correlation

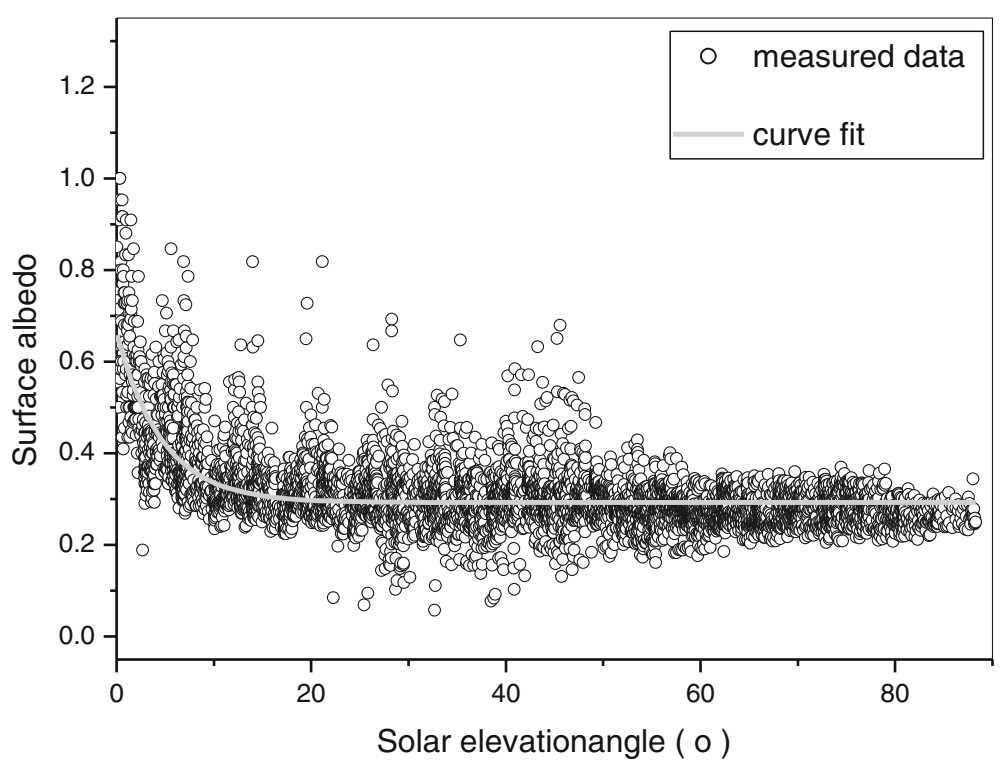

Figure 6. Half hourly variation of surface albedo with solar elevation angle during April 2010-March 2011. 


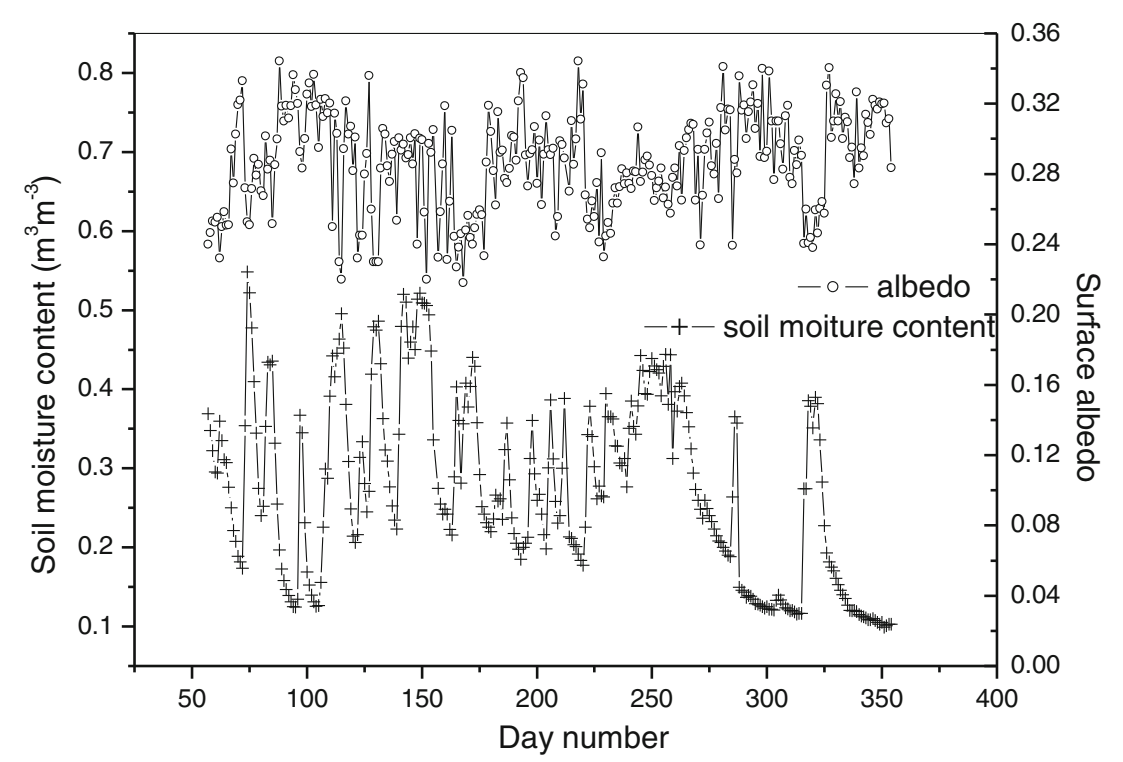

Figure 7. Daily variation of surface albedo and soil moisture content at $5 \mathrm{~cm}$ depth during April 2010-March 2011.

analysis because of the high variability of soil moisture content in this site. Thus the dependence of solar elevation angle on soil moisture content is overshadowed by the influence of soil moisture content which shows a large variability. Another reason possibly leading to the lower correlation could be the influence of clouds which could interfere with the scattering of short waves (Wang et al. 2005). In this section, the dependence of surface albedo on soil moisture content is analyzed on different time scales and the influence of cloud cover is also inquired.

The surface albedo calculated during measurements when the solar elevation angle lies in the range $50^{\circ}$ to $90^{\circ}$ was used for studying the influence of soil moisture. The relationship between the daily average surface albedo and soil moisture content at $5 \mathrm{~cm}$ is shown in figure 8 . The surface albedo decreases with increase in the soil moisture content. Both linear dependence and exponential relations have been reported earlier for fitting the variation of surface albedo with soil moisture content. Exponential fall of surface albedo with soil moisture content has been reported (Hoffer and Johannsen 1969; Lobell and Asner 2002; Liu et al. 2003; Guan et al. 2009). Also, the exponential relation is site dependent and is most pronounced for semi desert areas and least for crop lands (Wang et al. 2005; Liu et al. 2008b). In this study, the variation can be fitted using the equation $\alpha=$ $0.25588+010171 \exp \left(-\theta_{v} / 0.20394\right)$ were $\theta_{v}$ is the soil moisture content at $5 \mathrm{~cm}$. The correlation coefficient for the fit is 0.63 . As already stated cloud cover could influence the albedo thereby partially masking its dependence on moisture content.
Analysis was done using days with cloud cover less than 4 and 3 in a scale of 8 and the respective correlation coefficient for the fits are 0.43 and 0.42 . This leads to the conclusion that the influence of clouds is not the reason for lower correlation coefficient of the fit. The higher variability of albedo at each particular moisture content value could be due to the high variability of soil surface moisture content during all seasons as evident from figure 5. Gascoin et al. (2009) had studied the dependence of surface albedo on soil moisture content on the moraine of the Zongo glacier, Bolevia, a tropical site and obtained the exponential fall of albedo with soil moisture content. They also had pointed out that the experimental points were scattered about the curve fit probably due to the drying up of soil. Roxy et al. (2010) had studied the relationship between the surface albedo and the soil moisture content at Astronomical Observatory, Thiruvananthapuram using the data recorded during January to December 2008 and the exponential fit had a correlation coefficient of 0.56 .

An analysis of albedo and soil moisture content was done using monthly averages which corresponds to lower variability of soil moisture content and is shown in figure 9(a). The dependence can be fitted by the relation $\alpha=0.25413+$ $0.09029 \exp \left(-\theta_{v} / 0.27204\right)$. For the fitting routine, initial values were selected as the ones obtained by the earlier fit using daily averages. The correlation coefficient for the fit 0.76 is significantly higher than that obtained for daily averages thereby supporting the argument that the lower correlation in the analysis using daily averages is due to higher variability of soil moisture content. 


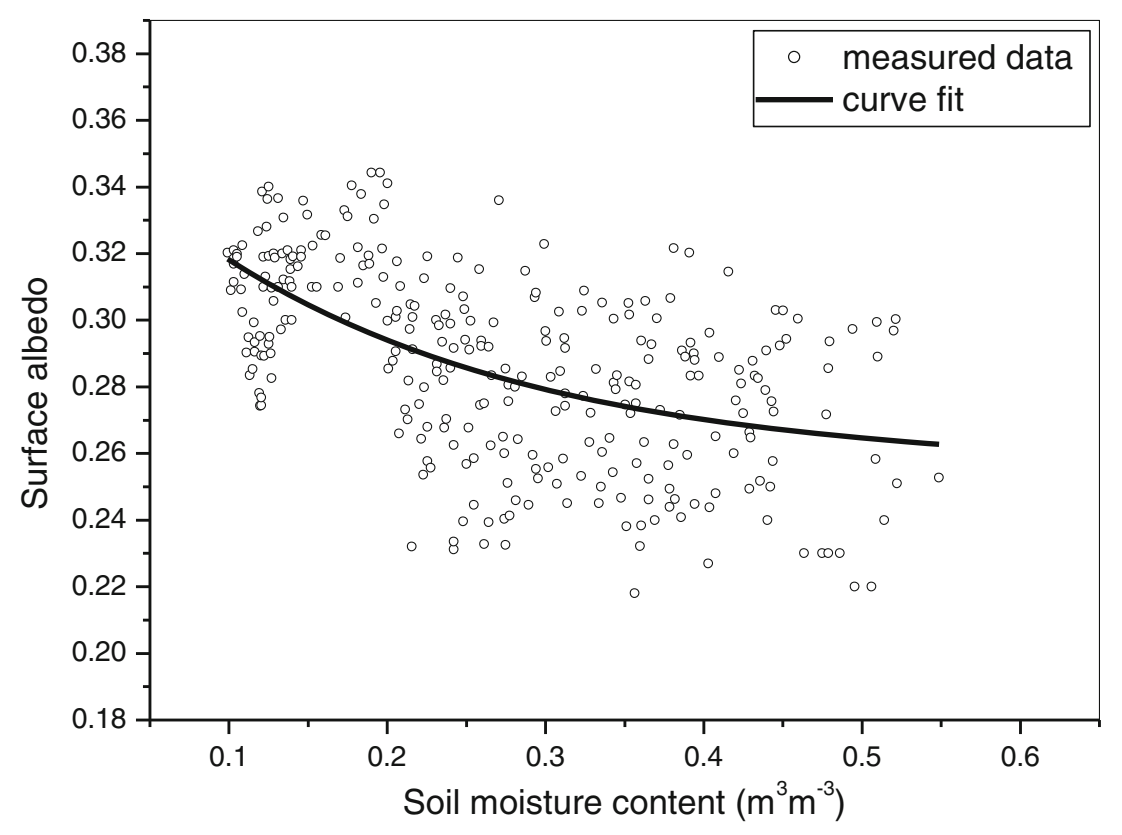

Figure 8. Daily average surface albedo versus soil moisture content at $5 \mathrm{~cm}$ depth.

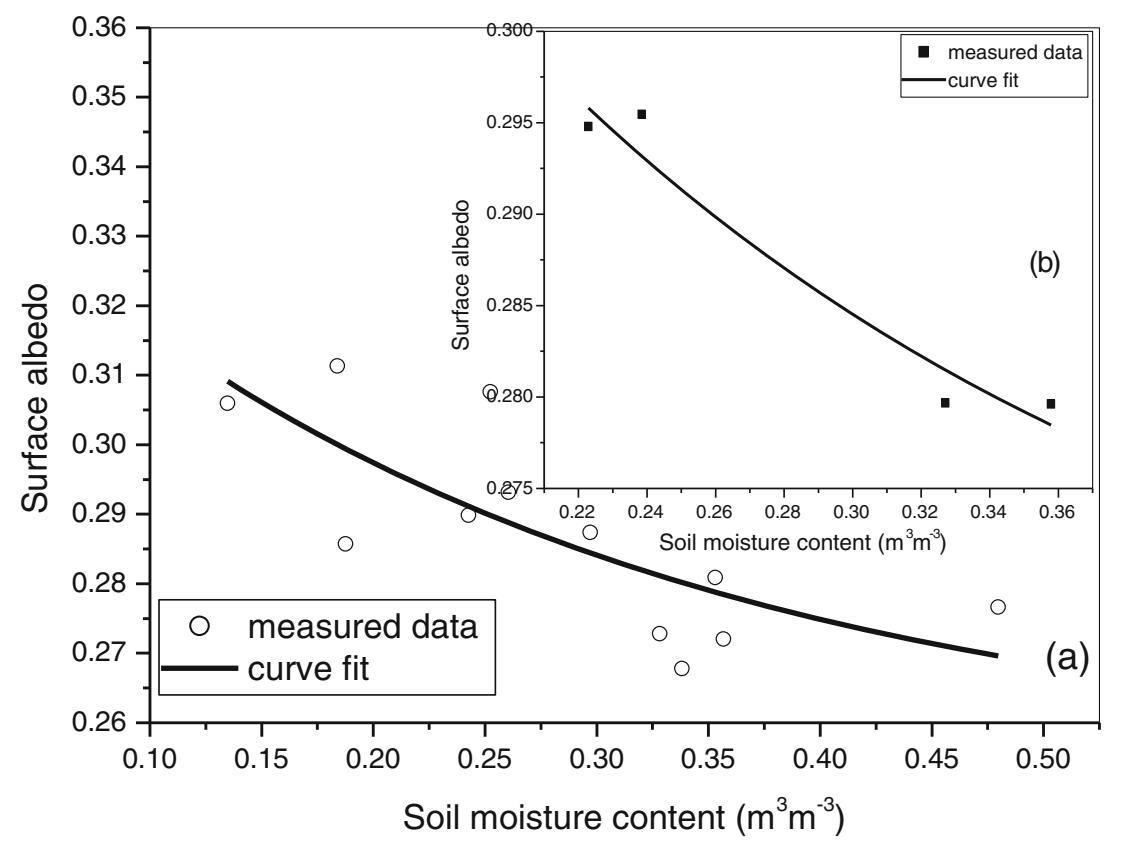

Figure 9. Surface albedo versus soil moisture content using (a) monthly average and (b) seasonal average.

The dependence of albedo on soil moisture content using seasonal average (figure $9 \mathrm{~b}$ ) leads to a relation $\alpha=0.26+0.1068 \exp \left(-\theta_{v} / 0.20394\right)$ with a correlation coefficient of 0.98 . The analysis on daily averages, monthly averages, and seasonal averages of surface albedo and soil moisture content showed an exponential fall. The lower correlation at daily scales is due to the high variability of soil moisture in all seasons. Also, the influence of cloud cover is insignificant.

\subsection{Variation of soil thermal parameters with soil moisture}

The dependence of soil thermal parameters on moisture content is very important for weather prediction models based on soil temperature (Hillel 2004). The energy budget at the soil-air interface depends on the soil thermal parameters that vary with soil moisture content. The soil thermal diffusivity, $D_{T}$, was estimated from the 
soil temperature values at 5 and $10 \mathrm{~cm}$ using equation (2) employing the amplitude method. The volumetric heat capacity and soil thermal conductivity, $k$, were estimated by the methods described in section 3 . The daily variation of the soil thermal parameters during the study period is shown in figure 10 . The thermal diffusivity values lie in the range $2.09 \times 10^{-7}-7.99 \times 10^{-7} \mathrm{~m}^{2} \mathrm{~s}^{-1}$. During all the seasons, sharply increased and decreased values could be noted in figure 10(a) which could be possibly due to the high variability in the moisture content. Roxy et al. (2010) had reported that the soil thermal diffusivity at Astronomical Observatory, Thiruvananthapuram lay in the range $2 \times 10^{-7}-15 \times 10^{-7} \mathrm{~m}^{2} \mathrm{~s}^{-1}$ during JanuaryDecember 2008. The average soil thermal diffusivity at Karyavattom, south Kerala another tropical site was reported to be respectively $0.633 \times 10^{-6}$, and $0.336 \times 10^{-6} \mathrm{~m}^{2} \mathrm{~s}^{-1}$ for wet $\left(\theta_{v}=0.32 \mathrm{~m}^{3} \mathrm{~m}^{-3}\right)$ and dry $\left(\theta_{v}=0.13 \mathrm{~m}^{3} \mathrm{~m}^{-3}\right)$ days (Tessy Chacko and Renuka 2002). The range of thermal diffusivity values obtained in the present study is comparable to that reported for many sites in India (Padmanabhamurthy et al. 1998; Anandakumar et al. 2001).

Volumetric heat capacity values lie in the range $1.58 \times 10^{6}-3.41 \times 10^{6} \mathrm{Jm}^{3} \mathrm{~K}^{-1}$. The variation of thermal conductivity more or less shows a similar trend as shown by the volumetric heat capacity. The values of thermal conductivity lay in the range $0.365-2.193 \mathrm{Wm}^{-1} \mathrm{~K}^{-1}$. The variation in these three parameters could be due to the high variability of daily soil moisture during all the seasons and their dependence on soil moisture content is studied below.

The dependence of thermal diffusivity on soil moisture content is reported to be complex and nonlinear in nature (Arkhangel'skaya 2009). The variation of daily average soil thermal diffusivity with daily average soil moisture content is shown in figure 11. Thermal diffusivity first increases abruptly with increase in soil moisture content till volumetric soil moisture content reaches about $0.15 \mathrm{~m}^{3} \mathrm{~m}^{-3}$ and then falls off. The falling is not as abrupt as the raise and the observed variation can be approximated by a log normal peak (Hillel 2004; Wang et al. 2005). The observed variation in the present case can be fitted by the relation $D_{T}=6.120 \times 10^{-7}+\left(3.7942 \times 10^{-8} / \theta_{v}\right) \exp (-$ $\left.\left(\ln \left(\theta_{v} / 0.1754\right)\right)^{2} /(0.1531)\right)$. The correlation coefficient for the fit is 0.55 . A similar relation between soil moisture content and thermal diffusivity is reported for a semi-desert site on the western Tibetan Plateau (Wang et al. 2005). However, the log normal dependence is site specific, as Guan et al. (2009) had reported a linear increase of thermal diffusivity with soil moisture content in a semi arid region. Analysis using monthly mean and seasonal mean values (not shown here) resulted in a decrease in the correlation of fit.

The variation of daily average soil thermal conductivity with soil moisture content is shown in figure 12(a). It is clear that with increase in moisture content, the soil thermal conductivity increases. This is due to the fact that the thermal conductivity of soil is mainly due to moisture

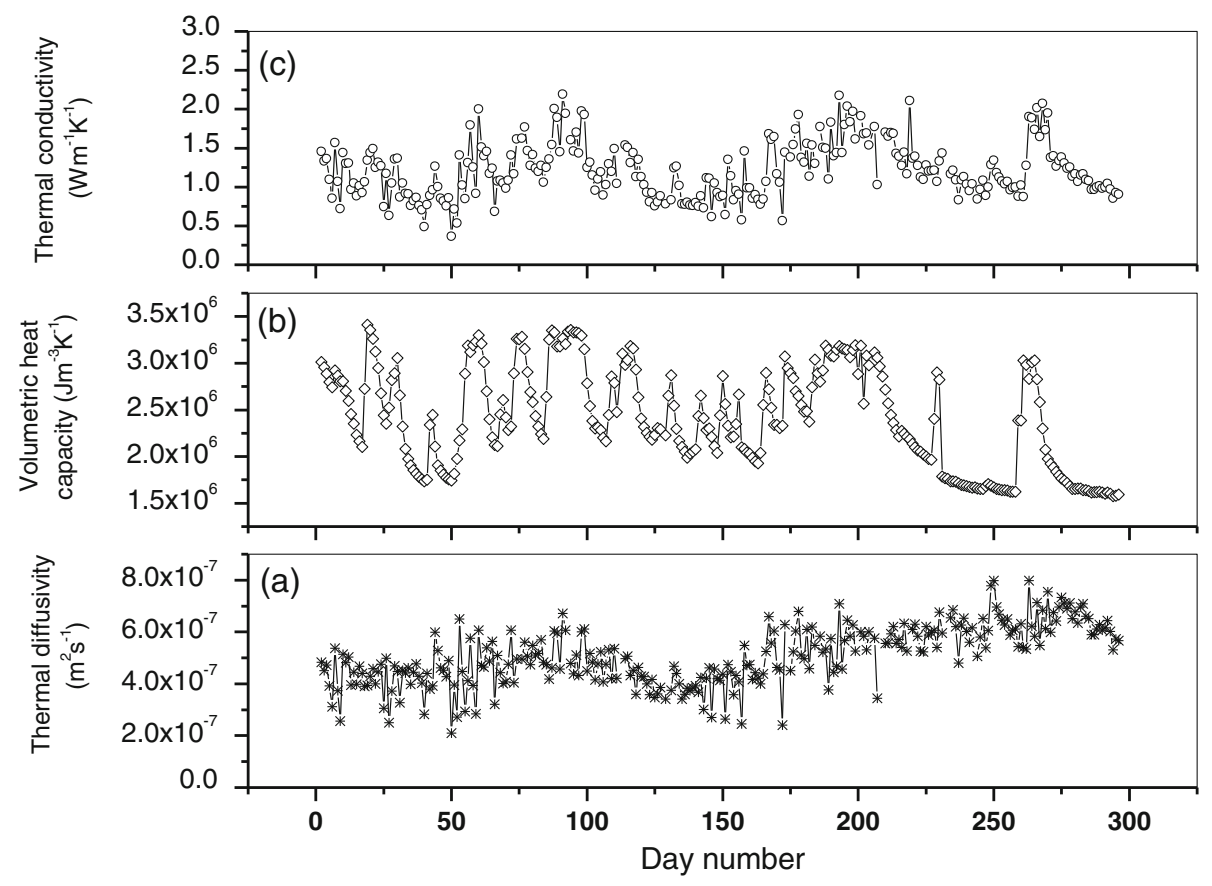

Figure 10. Daily variation of (a) thermal diffusivity, (b) heat capacity and (c) thermal conductivity during the period April 2010-March 2011. 


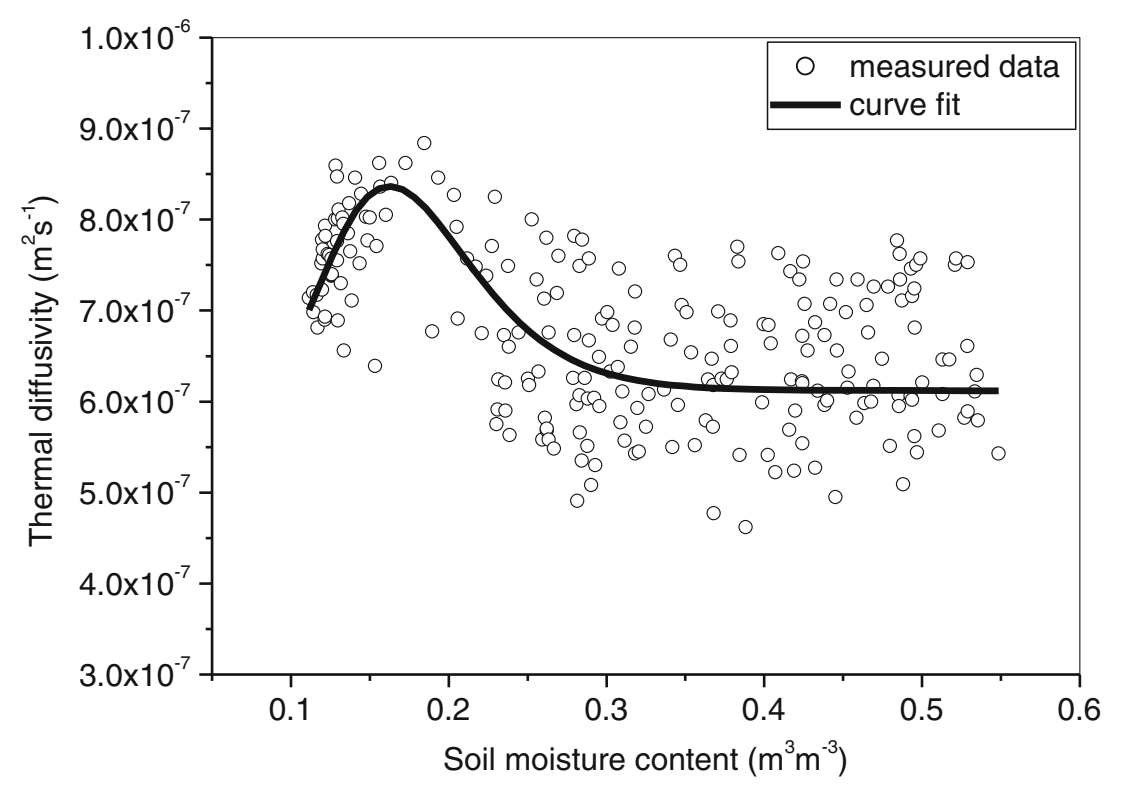

Figure 11. Daily average thermal diffusivity versus daily average soil moisture content.

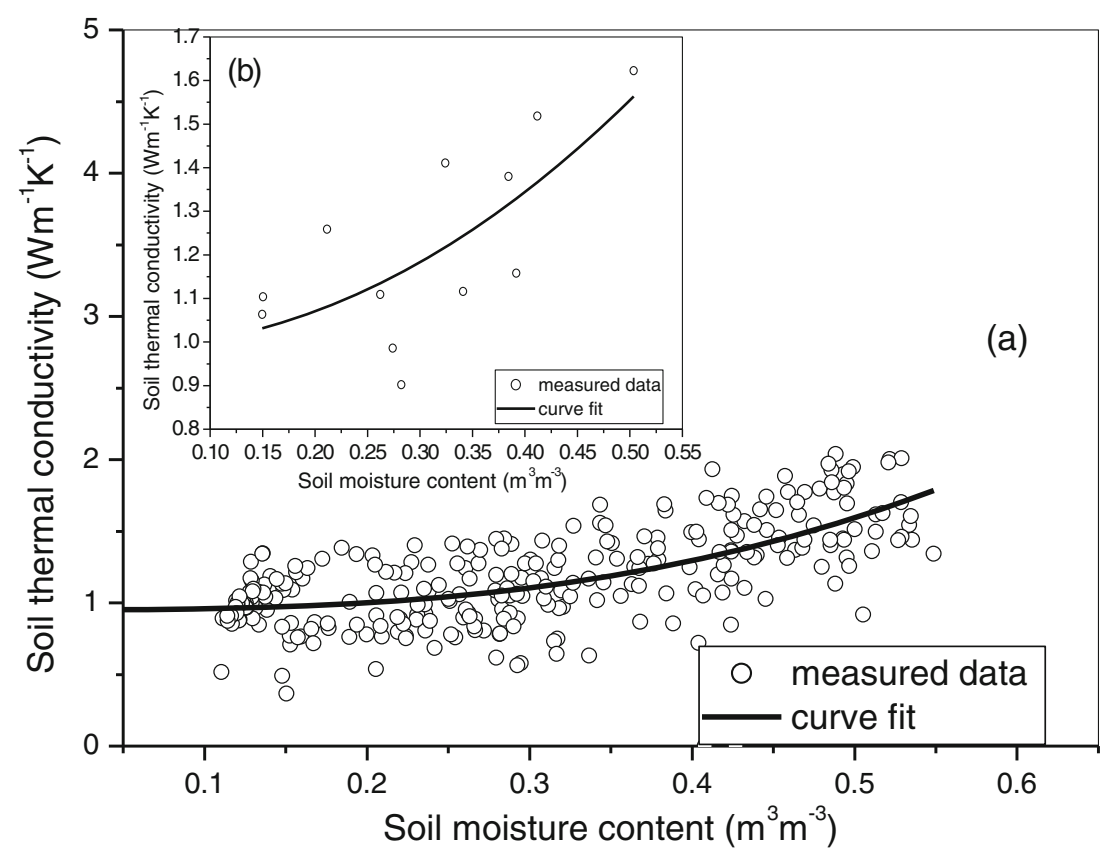

Figure 12. Variation of soil thermal conductivity with soil moisture content using (a) daily average and (b) monthly average.

content as it increases the thermal connectivity (Hillel 2004). Presence of water films at contact points improves the thermal contact and also replaces air in the soil pore space (Baver et al. 1972; Hanks and Ashcroft 1986). With decrease in moisture content, the pores are filled with air, which is a bad conductor in comparison with water thereby decreasing thermal conductivity. The variation of soil thermal conductivity with soil moisture is usually reported to be of the form $k=a+b \theta_{v}^{c}$ where $a, b$, and $c$ are constants (Hillel 2004). In the present case, the fitting procedure resulted in a relation of the form $k=0.9517+4.4820 \theta_{v}^{2.8029}$. The dependence of soil thermal capacity on soil moisture content in the present study is unlike many cases where power law dependents with exponents less than 1 were reported (Wang et al. 2005). The correlation coefficient for the fit is 0.65. Analyses using monthly average (figure 12b) and seasonal average result in better fits with correlation coefficients 0.74 and 0.78 , respectively. Relations for monthly and 
seasonal averages are respectively $k=0.9844+$ $2.3863 \theta_{v}^{2.0643}$ and $k=0.8603+2.3193 \theta_{v}^{1.6937}$.

\section{Conclusions}

Surface albedo, soil thermal diffusivity, and thermal conductivity are important parameters which determine the subsurface soil thermal profile and energy budget at the land-atmosphere, and thereby determine the boundary-layer climate. All these parameters depend on the soil moisture content. A detailed investigation of the variability of soil moisture content on different time scales is done. Large variability in soil moisture content during all seasons is noted. The relationship between surface albedo and soil moisture content revealed an exponential dependence. The dependence of cloud cover on surface albedo was found to be insignificant. The use of monthly and seasonal averages decreased the variability of soil moisture content and made the dependence of surface albedo on moisture content more discernable. The soil moisture content dependence of soil thermal diffusivity and thermal conductivity can be fitted by a log normal relation and power law respectively.

\section{Acknowledgements}

One of the authors Neena Sugathan acknowledges financial assistance from University Grants Commission (UGC), Government of India for fellowship under the Faculty Development Programme (FDP). Authors acknowledge Central Soil Analytical Laboratory (Government of Kerala), Thiruvananthapuram for soil analysis and India Meteorological Department (IMD), Thiruvananthapuram for rainfall and cloud cover data. The authors are grateful to the anonymous reviewers for their constructive comments.

\section{References}

Anandakumar K, Venkatesan R and Prabha T V 2001 Soil thermal properties at Kalpakkam in coastal south India; Proc. Indian Acad. Sci. (Earth Planet. Sci.) 110(3) 239-245.

Arkhangel'skaya T A 2009 Parameterization and mathematical modeling of the dependence of soil thermal diffusivity on the water content; Eurasian Soil Sci. 42(2) $162-172$.

Baldocchi D D, Vogel C A and Hall B 1997 Seasonal variation of energy and water vapor exchange rates above and below boreal jack pine forest canopy; J. Geophys. Res. 102(D24) 28,939-28,951, doi: 10.1029/96JD03325.

Baver L D, Gardner W H and Gardner N R 1972 Soil Physics; 4th edn (New York: John Wiley and Sons).

Bowers S A and Hanks R J 1965 Reflection of radiant energy from soils; Soil Sci. 100 130-138.
Gascoin S, Ducharne A, Ribstein P, Perroy E and Wagnon P 2009 Sensitivity of bare soil albedo to surface soil moisture on the moraine of the Zongo glacier (Bolivia): Implications for land surface modeling; Geophys. Res. Lett. 36 L02405, doi: 10.1029/2008GL036377.

Guan X D, Huang J P, Guo N, Bi J R and Wang G Y 2009 Variability of soil moisture and its relationship with surface albedo and soil thermal parameters over the Loess plateau; Adv. Atmos. Sci. 26(4) 692-700.

Hanks R J and Ashcroft G L 1986 Applied Soil Physics (Berlin: Springer-Verlag).

Hillel D 2004 Introduction to Environmental Soil Physics (California: Elsevier Academic Press), pp. 14-15.

Hoffer R M and Johannsen C J 1969 Ecological potential in spectral signatures analysis; In: Remote sensing in Ecology (ed.) Johnson P L (Athens, GA: University of Georgia), pp. 1-16.

Horton R, Wierenga P J and Nielsen D R 1983 Evaluation of methods for determining the apparent thermal diffusivity of soil near the surface; Soil Sci. Soc. Am. J. 47 25-32.

Huang J P, Zhang W, Zuo Q, Bi J R, Shi J S, Wang X, Chang Z L, Huang Z W, Yang S, Zhang B D, Wang G Y, Feng G H, Yuan J Y, Zhang L, Zuo H C, Wang S G, Fu C B and Chou J F 2008 An overview of the semi-arid climate and environment research observatory over the Loess Plateau; Adv. Atmos. Sci. 25(6) 906-921.

Idso S B, Jackson R D, Reginato R J, Kimball B A and Nakayama F S 1975 The dependence of bare soil albedo on soil water content; J. Appl. Meteorol. 14 109-113.

Kasubuchi T 1975 The effect of soil moisture on thermal properties in some typical Japanese upland soils; Soil Sci. Plant Nutr. 21 107-112.

Li Y and Hu Z Y 2009 A study on parameterization of surface albedo over grassland surface in the northern Tibetan plateau; Adv. Atmos. Sci. 26(1) 161-168.

Liang S and Townshend J R G 1996 A modified Hapke model for soil bidirectional reflectance; Remote Sens. Environ. 55 1-10.

Liu W D, Baret F, Gu X F, Zhang B, Tong Q X and Zhang L F 2003 Evaluation of method for soil surface moisture estimation from reflectance data; Int. J. Remote Sens. 24 2069-2083.

Liu H, Tu G and Dong W J 2008a Three-year changes of surface albedo of degraded grassland and cropland surfaces in a semiarid area; Chinese Sci. Bull. 53 1246-1254.

Liu H Z, Wang B M and Fu C B 2008b Relationship between surface albedo, soil thermal parameters and soil moisture in the semi-arid area of Tongyu, northeastern China; Adv. Atmos. Sci. 25(5) 757-764.

Lobell D B and Asner G P 2002 Moisture effects on soil reflectance; Soil Sci. Soc. Am. J. 66 722-727.

Menon P A and Rajan C K 1989 Climate of Kerala (Cochin: Classic Publications).

Oke T R 1987 Boundary Layer Climates, 2nd edn (London: Methuen \& Co. Ltd.), pp 339-356.

Padmanabhamurthy B, Amaralingeswara Rao $\mathrm{K}$ and Mukherjee R 1998 A preliminary analysis of soil temperature at five different sites under land surface processes experiment in Sabarmati river basin; Indian J. Radio. Space Phys. 27(5) 199-206.

Robock A, Vinnikov K Y, Srinivasan G, Entin J K, Hollonger S E, Speranskaya N A, Liu S and Namkahi A 2000 The global soil moisture data bank; Bull. Am. Meteor. Soc. 81 1281-1299.

Roxy M S, Sumithranand V B and Renuka G 2010 Variability of soil moisture and its relationship with surface albedo and soil thermal diffusivity at Astronomical 
Observatory, Thiruvananthapuram, south Kerala; J. Earth Syst. Sci. 119(4) 507-517.

Tessy Chacko P and Renuka G 2002 Temperature mapping, thermal diffusivity and subsoil heat flux at Kariavattom of Kerala; Proc. Indian Acad. Sci. (Earth Planet. Sci.) 111(1) 79-85.

Todd S W and Hoffer R M 1998 Response of spectral indices to variations in vegetation cover and soil background; Photogramm. Eng. Remote Sens. 64(9) 915-921.

Usowicz B 1993 Thermal properties of some soils from lower Austria, central Bohemia and Lublin upland; Int. Agrophys. 7 183-191.

Usowicz B, Lipiec J, Usowicz J B and Marczewski W 2013 Effect of aggregate size on soil thermal conductivity:
Comparison of measured and model-predicted data; Int. J. Heat Mass Transfer. 57 536-541.

Wang Y and Shen G 2013 The primary and secondary analysis of uncertain factors in soil thermal properties of GSAP; Adv. Mater. Res. 614-615 688-694.

Wang K C, Wang P C, Liu J M, Sparrow M, Haginoya S and Zhou X J 2005 Variation of surface albedo and soil thermal parameters with moisture content at a semidesert site on the western Tibetan plateau; Bound.-Layer Meteorol. 116 117-129.

Wang G, Huang J, Guo W, Zuo J, Wang J, Bi J, Huang Z and Shi J 2010 Observation analysis of land-atmosphere interactions over the Loess Plateau of northwest China; $J$. Geophys. Res. 115 D00K17, doi: 10.1029/2009JD013372.

MS received 13 September 2013; revised 12 February 2014; accepted 15 February 2014 